the Industrial Health Research Board's Report on the Toxicity of Industrial Organic Solvents (H.M. Reports No. 80, 1952) by the same author: This book confines itself to those industrial solvents that are known to constitute a definite health hazard, and page numbers have been reduced further by omitting references to animal experiments and the original literature. Lucidly written new contributions constitute the general chapters dealing with the physical and chemical characteristics of organic solvents, their physiological effects and the precautions against their health hazards. Particular stress is laid on the blood changes as in some cases of poisoning without symptoms they constitute the only positive evidence. A glossary of medical terms and good index, freedom from printing and other errors and the low price should make this volume an invaluable work of reference to the factory doctor and manager alike.

E.K.

\section{A HANDBOOK ON DISEASES OF CHILDREN}

By Bruce Williamson, : M.D., F.R.C.P. 7th Edition. Pp. xi +467 , with 103 illustrations. Edinburgh: E. \& S. Livingstone, Ltd. 1953. 2 Is.

\section{AIDS TO THE DIAGNOSIS AND TREATMENT OF DISEASES OF CHILDREN}

By F. M. B. Allen, M.D., F.R.C.P., and O. D. FISHER, M.D., M.R.C.P., D.C.H. 9th Edition. Pp. viii +300 . London: Baillière, Tindall $\&$ Cox. 1953. 8s. 6d.

Of what use is a small textbook on a large subject? It might serve firstly as an introduction to the subject, secondly as a handy work of reference or, thirdly, as a revision book for the examination candidate. As introductions to the study of diseases of children for the student, both these textbooks must be regarded as unsuitable on account of the limited space they are able to devote to the pathology and the nature of the disordered physiology in each disease, not to mention the exclusion of matter devoted to the normal infant and child and his growth and development. As works of reference for the practitioner they are likely to prove a disappointment simply on account of their small size, in spite of the inclusion of tables of diets, sections on antibiotics, lists of prescriptions and other useful information. Their value, therefore, must be judged on the basis of their suitability as revision books for examinations.

In the new edition of the 'Handbook on Diseases of Children' recent advances in paediatrics are adequately represented and yet the book retains a rather old-fashioned air. This is not likely to prove a disadvantage in examinations as examiners tend to be elderly persons. On the other hand, sections of the book present a somewhat unusual and personal approach to their subjects, which, while they make the book the more interesting of the two for the reviewer, are likely to prove a drawback for the examination candidate for whom con- ventional uniformity of opinion is the best policy.

The 'Aids' is safer; recent information is well integrated into the whole and the most important facts about each subject are cleverly condensed into a miniumum of words.

To the examination candidate the reviewer would recommend 'the 'Aids' rather than the 'Handbook' as better value for his money. The 'Handbook,' however, remains popular amongst students; this is perhaps in part due to a superficial comprehensiveness and in part to the good binding, agreeable format and print and the many small illustrations (some of little obvious value) which dot its pages like raisins in a suet pudding.

Its author has much valuable advice to give and interesting things to say; but instead of an eighth edition again scantily covering all children's diseases, however rare, and again adding further recent advances, let us hope for a new book based on the author's long personal experience in paediatrics and on his stimulating opinions.

As for the 'Aids,' long may it flourish and bring its concentrated and yet palatable nourishment to students.

\section{TEXTBOOK OF PUBLIC HEALTH}

By W. M. Frazer, O.B.E., M.D., Ch.B., M.Sc., D.P.H. I 3 th Edition. Pp. xi +663 , with 76 - illustrations. Edinburgh: E. \& S. Livingstone Ltd. 1953. 42s.

With the decease of the two original authors, Drs. Hope and Stallybass, the latest (1 $3^{\text {th }}$ ) edition of this standard textbook on public health has passed entirely under the editorship of Dr. W. M. Frazer, until recently the Medical Officer of Health for Liverpool and Professor of Public Health in that university. This book is intended principally for D.P.H. students, medical officers of health and others interested in the administrative aspects of preventive medicine. In this respect it is a mine of most useful information on environmental factors, e.g. climate, housing, lighting and ventilation, the hygiene of water, milk and food, sewage disposal, etc., which affect the health of the community. The provision of and legislative measures affecting such services as maternity and child welfare, school health, mental health, the blind, tuberculosis and venereal diseases are also fully described.

A weak section of the book is the chapter dealing with the epidemiology and prevention of infectious diseases which shows a lack of awareness of recent knowledge and contains some misleading statements. For example, it would appear that combined active immunisation with scarlatinal toxin and diphtheroid toxoid is regarded as a practicable procedure (page 378 ), that antimeningococcal serum is still being used in the treatment of cerebrospinal meningitis (page 383) and that the Pasteurian method of immunization against rabies is a common practice (page 393). Pneumonia is said to be caused by four virulent pneumococeus types of which carriers are common (page 364 ) while in regard to Sonne dysentery (which is not caused by Sh. 